\title{
Semi-Automated PCR Method for Quantitating MDR1 Expression
}

\author{
S. Zhao, U. Consoli, R. Arceci ${ }^{1}$, J. Pfeifer ${ }^{2}$, W.S. Dalton ${ }^{3}$ and M. Andreeff \\ The University of Texas M.D. Anderson Cancer Center, Houston, TX; ${ }^{1}$ Dana Farber \\ Cancer Center, Boston, MA; ${ }^{2}$ Perkin-Elmer/Applied Biosystems Division, Foster City, \\ $\mathrm{CA}$; and ${ }^{3}$ University of Arizona, Tucson, AZ, USA
}

BioTechniques 21:726-731 (October 1996)

\begin{abstract}
The MDRl gene is involved in drug resistance in many hematopoietic and solid tumors. The Quantitative PCR System $5000^{\mathrm{TM}}$ (QPCR-5000; Perkin-Elmer) is a new instrument system that uses electrochemiluminescence to automatically quantitate polymerase chain reaction (PCR) products. A comparative study between radioactively labeled $P C R\left({ }^{32} P-P C R\right)$ and $Q P C R$ was performed to analyze the MDR1 gene expression in the drug-resistant (Doxorubicin) cell lines Dox40, Dox6, the parental cell line 8226/S, CEM Doxl and three acute myeloid leukemia (AML) patient samples. Using the Dox40 and Dox6 resistant cell lines, we compared the sensitivities of QPCR and ${ }^{32} P-P C R$. A strong signal was obtained from QPCR at 20 to 25 cycles (which is in the linear range for quantitation), while a weak signal was obtained using ${ }^{32} P-P C R$ at the same cycle number. Dilution experiments gave better precision with the QPCR than with the radioactive method. AML samples were studied with the MDR1-specific MAbs MRK16 and 4E3, and the efflux function was analyzed using Rh-123 retention in the absence or presence of verapamil. The three samples showed high $(D=0.79)$, medium $(D=0.52)$ and negative $(D=0.08)$ p-glycoprotein $(P-g p)$ levels and correlated with efflux function. The MDR $1 / \beta_{2}-M$ mRNA ratios for ${ }^{32} P-P C R$ were $0.41,0.40$ and 0.12 , respectively, and were $0.127,0.097$ and 0.028, respectively, for QPCR. There were significant differences between the samples with high and medium $P$-gp levels comparing the two methods. Very low levels of MDR1 in CEM Doxl cells could be detected only by QPCR. In conclusion, QPCR was found to be more reproducible, accurate and sensitive than ${ }^{32} P-P C R$.
\end{abstract}

\section{INTRODUCTION}

The MDR1 gene has been associated with resistance to a number of naturally occurring and synthetic drugs in cancer chemotherapy $(1,5,11)$. The gene codes for a $170-\mathrm{kDa}$ glycoprotein $(\mathrm{P}-\mathrm{gp})$ that is localized at the plasma membrane. This $\mathrm{P}$-gp functions as an energy-dependent efflux pump, transporting molecules from the interior of the cells to the outside. MDR1 expression has been correlated with the response of hematopoietic malignancies and solid tumors to chemotherapy $(7,8,10)$. Measuring the level of MDR1 expression before cytotoxic therapy, therefore, has important clinical implications including attempts to block MDR with verapamil, cyclosporine A, tamoxifen and second-generation MDR blockers including PSC833 and Dexniguldipine. At present, the most common, fast and powerful method to detect MDR1 expression is polymerase chain reaction (PCR) of MDR1 mRNA following reverse transcription (RT). Among other considerations, the success of quantitative PCR depends on the technique used to detect the amplified products. Because of variations seen with ethidium bromide staining, many laboratories are using radioactivity for detection, whether by direct incorporation, primer labeling, radioactive probes for Southern blots or internal standards $(1,4,12)$. The QPCR$5000^{\mathrm{TM}}$ method (QPCR; Perkin-Elmer, Norwalk, CT, USA) is a new nonradioactive, non-gel based system that can quantitatively detect PCR products. The QPCR uses an electrochemiluminescence process to detect the presence of a TBR molecule [tris $\left(2,2^{\prime}\right.$-bipyridine) ruthenium (II) chelate], which 
is a nonradioactive tag that can be placed on the $5^{\prime}$ terminus of any PCR primer or probe. This paper reports a comparative study of quantitation between ${ }^{32} \mathrm{P}-\mathrm{dCTP}$ incorporation and the QPCR for quantitative PCR. The MDR1 mRNA, P-gp levels and efflux activities were determined for system cell lines with different amounts of MDR1 mRNA, including 8226/Dox40 and 8226/Dox 6 (resistant), 8226/S (sensitive), CEM Dox 1 and three acute myeloid leukemia (AML) patient samples. The results demonstrate that the QPCR method is significantly more advantageous than the ${ }^{32} \mathrm{P}$-incorporation method for quantitative detection of PCR products.

\section{MATERIALS AND METHODS}

\section{Cells and Cell Culture}

Patient samples, obtained from Dr. Cheryl Wilmans, were supplied for the MDR1 Detection Methods Workshop at St. Jude's Children's Research Hospital (Memphis, TN, USA). 8226/Dox40, 8226/Dox6 and CEM Dox1 drug-resistant cell lines, and the 8226/S drug-sensitive parental cell line were cultured in RPMI 1640 medium plus $10 \%$ fetal calf serum (FCS), $1 \%$ ampicillin and $1 \%$ streptomycin. The cells were incubated in a $37^{\circ} \mathrm{C}$ incubator containing $5 \% \mathrm{CO}_{2}$.

\section{RNA Isolation and Reverse Transcription}

RNA was isolated according to the single-step acid guanidinium thiocyanate-phenol-chloroform method (2). Purified RNA samples were quantitated using a DU-640 spectrophotometer (Beckman Instruments, Fullerton, CA, USA). A reverse-transcription (RT) kit was used to synthesize cDNA, according to the manufacturer's instructions (Boehringer Mannheim, Indianapolis, IN, USA). One microgram of total RNA template was used per $10 \mu \mathrm{L}$ of RT reaction.

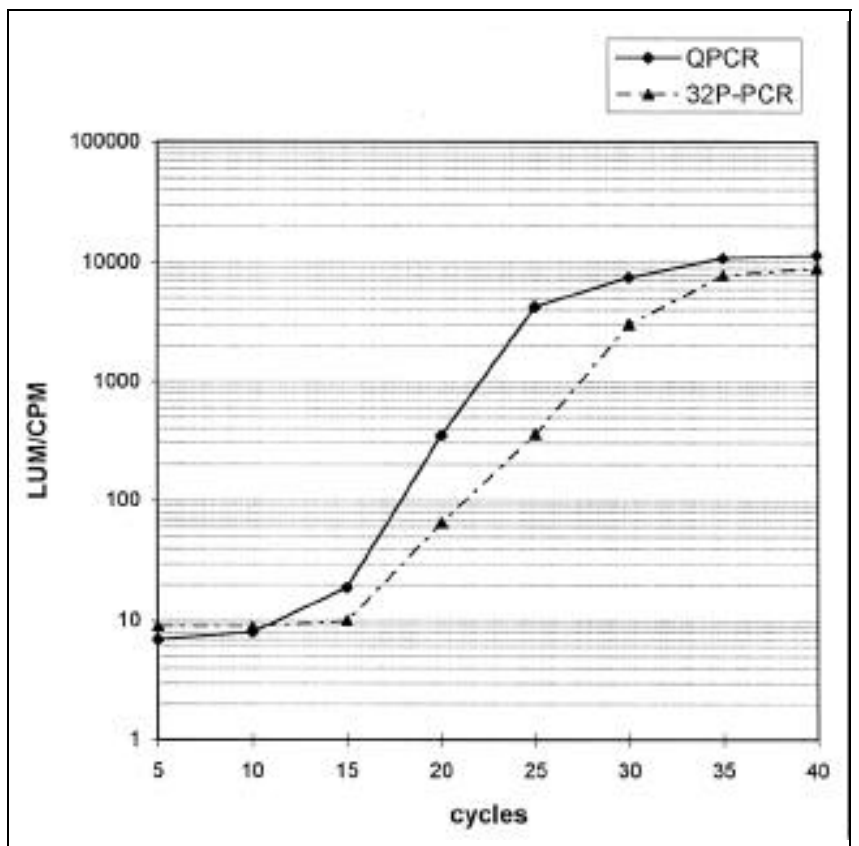

Figure 1. Quantitation of the MDR1 PCR product by the QPCR and 32P-labeling methods at various cycle numbers using the Dox40 drug-resistant cell line. PCR reaction tubes that contained the same amount of cDNA template were amplified at 5-40 cycles. The PCR products were quantitated by the two methods (see Materials and Methods). 


\section{Primers}

MDR1 and $\beta_{2}$-microglobulin $\left(\beta_{2}-\mathrm{M}\right)$ primers (12) were synthesized on an Applied Biosystems oligonucleotide synthesizer (Model 392; Perkin-Elmer/Applied Biosystems Division, Foster City, CA, USA). The TBR-labeled and biotin-labeled primers were obtained from Baron Biotech (Milford, CT, USA). The labeled primers were purified by high-performance liquid chromatography (HPLC).

\section{Amplification and Detection Using ${ }^{32} \mathbf{P}$ Incorporation}

One-tenth of the RT reaction was used for each PCR, for a total volume of $25 \mu \mathrm{L}$. MDR1 and $\beta_{2}$-M cDNAs were amplified simultaneously in separate $0.2-\mathrm{mL}$ MicroAmp ${ }^{\circledR}$ tubes (Perkin-Elmer). The conditions for each reaction were as follows: $1.0 \mu \mathrm{M}$ primers (each), $0.2 \mu \mathrm{L}$ of $25 \mathrm{mM}$ dNTP, $2 \mu \mathrm{Ci}$ ${ }^{32} \mathrm{P}-\alpha$-dCTP, $2.5 \mu \mathrm{L}$ of $10 \times$ PCR buffer and $1.5 \mathrm{U}$ AmpliTaq ${ }^{\circledR}$ DNA Polymerase (Perkin-Elmer). The thermal cycling was performed in a GeneAmp ${ }^{\circledR}$ PCR System 9600 (Perkin-Elmer) using the following parameters: 28 cycles of $94^{\circ} \mathrm{C}$ for $30 \mathrm{~s}$, $63^{\circ} \mathrm{C}$ for $30 \mathrm{~s}$ and $72^{\circ} \mathrm{C}$ for $45 \mathrm{~s}$, followed by a 10 -min postextension step at $72^{\circ} \mathrm{C}$. Following thermal cycling, $3.0 \mu \mathrm{L}$ of the PCR was analyzed on an $8 \%$ polyacrylamide gel. Electrophoresis was performed for $3 \mathrm{~h}$ at $300 \mathrm{~V}$. The radioactive products were detected and quantitated on the Betascope ${ }^{\mathrm{TM}}$ 603 (Betagen, Waltham, MA, USA) for $30 \mathrm{~min}$, with exposure after on Kodak film (Eastman Kodak, Rochester, NY, USA) at $-70^{\circ} \mathrm{C}$ for $4-8 \mathrm{~h}$ without an intensifying screen. All experiments were performed in duplicate.

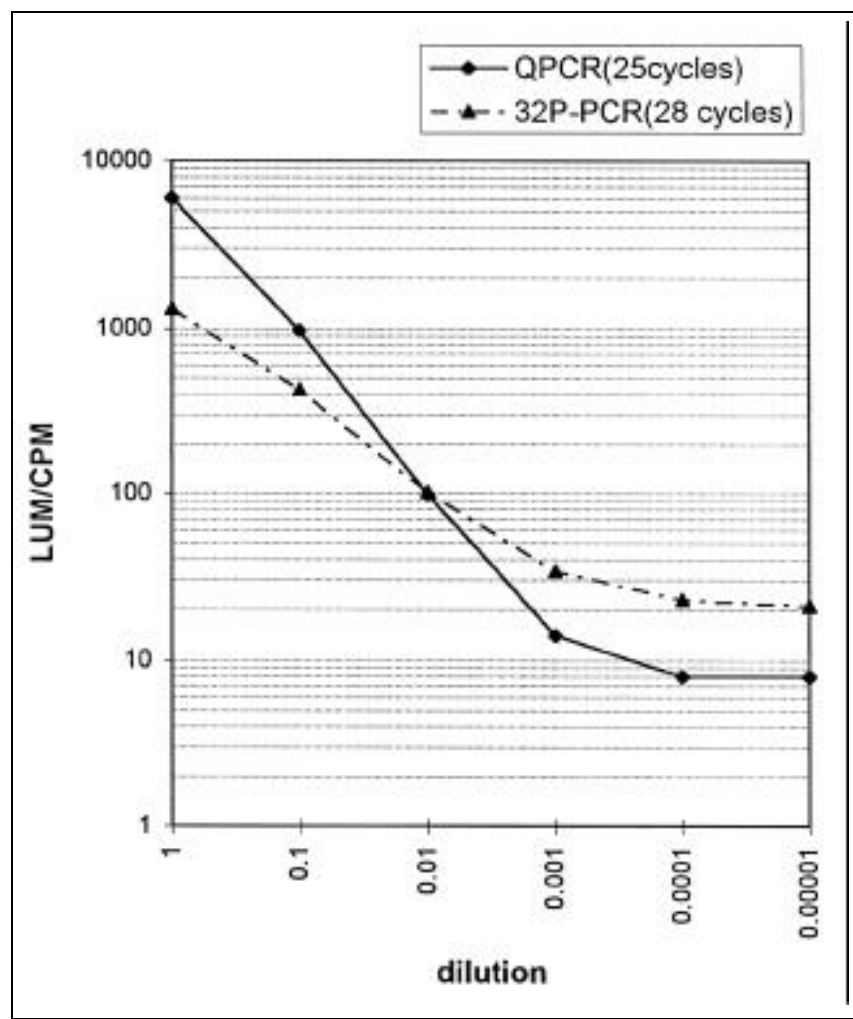

Figure 2. Detection of amplified PCR product by the two methods with 1:10 dilution steps of cDNA template. PCR was performed for 25 cycles for QPCR and 28 cycles for ${ }^{32} \mathrm{P}-\mathrm{PCR}$ (very weak signal at 25 cycles) by serial dilution of Dox 40 cDNA. The correlation between dilution and PCR product is compared for the two methods.

\section{Amplification and Detection Using the QPCR-5000 System}

PCR conditions used were the same as those indicated above, with the exception that the primer concentrations were $0.2 \mu \mathrm{M}$ (each) and only 25 cycles were performed. Following PCR, $1 \mu \mathrm{L}$ of the reaction was incubated with $49 \mu \mathrm{L}$ of $1 \times$ PCR reaction buffer and $15 \mu \mathrm{L}$ of QPCR streptavidin-coated ferrous beads (Perkin-Elmer) at room temperature for $20 \mathrm{~min}$. Following this step, $335 \mu \mathrm{L}$ of QPCR Assay Buffer (PerkinElmer) were added, and the samples were analyzed using the QPCR-5000 System according to the manufacturer's instructions.

\section{Northern Dot Blot Analysis}

Ten micrograms of total RNA were denatured and put on a dot blot manifold. Hybridization was carried out at $42^{\circ} \mathrm{C}$ for $20 \mathrm{~h}$ with a hybridization solution containing $50 \%$

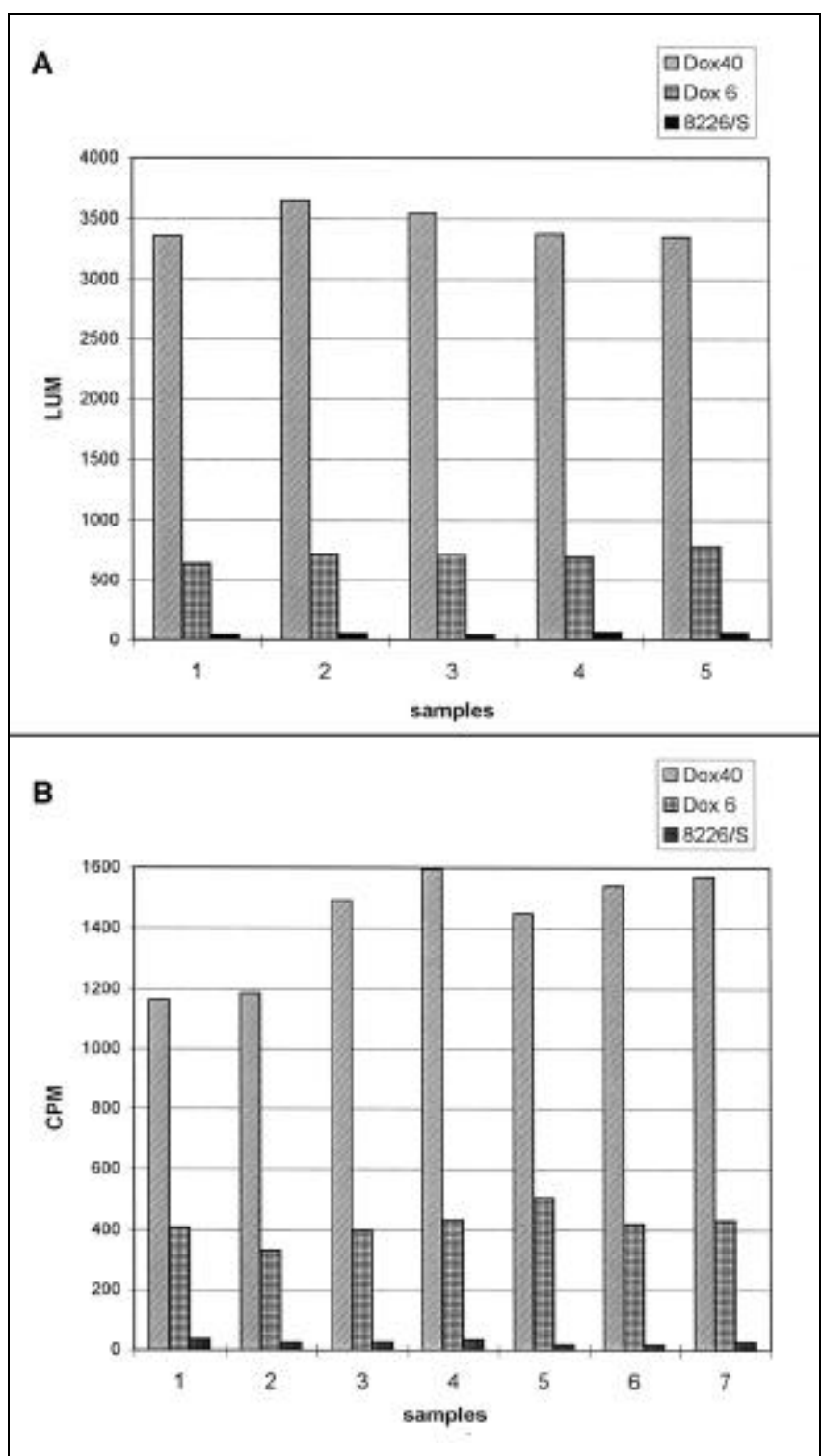

Figure 3. Evaluation of variation by QPCR (A) and ${ }^{32}$ P-PCR (B) for the MDR1 gene. Multiple tubes containing the same amount of cDNA template from Dox40, Dox6 and 8226/S cells were amplified simultaneously. The differences for the whole PCR process and measurements were calculated from tube to tube. 
formamide, $1 \%$ Denhardt's, $5 \times$ sodium chloride-sodium phosphate-EDTA (SSPE), $0.5 \%$ dextran sulfate, $0.5 \%$ sodium dodecyl sulfate (SDS) and $200 \mu \mathrm{g} / \mathrm{mL}$ salmon sperm DNA. The MDR1 and $\beta$-actin probes were obtained from Oncor (Gaithersburg, MD, USA). After hybridization, the filters were washed under highly stringent conditions. The signals were analyzed with a Betascope-603.

\section{Flow Cytometry, Antibodies and Immunofluorescence}

The protocol is the same as previously published (3). Briefly, the monoclonal antibodies MRK-16 and 4E3 were used to detect the MDR1 P-glycoprotein. One hundred microliters of phosphate-buffered saline (PBS), without $\mathrm{Ca}^{2+}$ or $\mathrm{Mg}^{2+}$ (Sigma Chemical, St. Louis, MO, USA), containing 2 $\times 10^{6}$ cells/tube and 1:1 dilution of human serum were incubated at $4^{\circ} \mathrm{C}$ for $30 \mathrm{~min}$ to inhibit nonspecific binding of antibodies. Two milliliters of PBS were then added to the cells, followed by centrifugation at $600 \times g$ for $5 \mathrm{~min}$. The pelleted cells were resuspended in $100 \mu \mathrm{L}$ of PBS containing $1 \%$ bovine serum albumin (BSA) and $10 \mu \mathrm{g} / \mathrm{mL}$ of the anti P-gp $\mathrm{MAb}$ or isotype-matched nonreactive control. This mixture was incubated for $30 \mathrm{~min}$ at $4^{\circ} \mathrm{C}$, and the cells were washed twice with cold PBS followed by resuspension in $100 \mu \mathrm{L}$ of PBS containing 1\% BSA and secondary antibody fluorescein isothiocyanate (FITC)-conjugated goat antimouse immunoglobulin (Becton Dickinson, Franklin Lakes, NJ, USA). The cells were incubated with the second antibody for $30 \mathrm{~min}$ at $4{ }^{\circ} \mathrm{C}$ in the dark followed by two washes in cold PBS. The samples were then analyzed immediately, and the level of Pgp expression was determined by Kolmogorov-Smirnov analysis (14) using a FACScan ${ }^{\mathrm{TM}}$ (Becton Dickinson) with Lysys II software as previously described (9). The assay for the efflux of Rh-123 (Sigma Chemical) was performed as previously described (3). The cells were incubated with 200

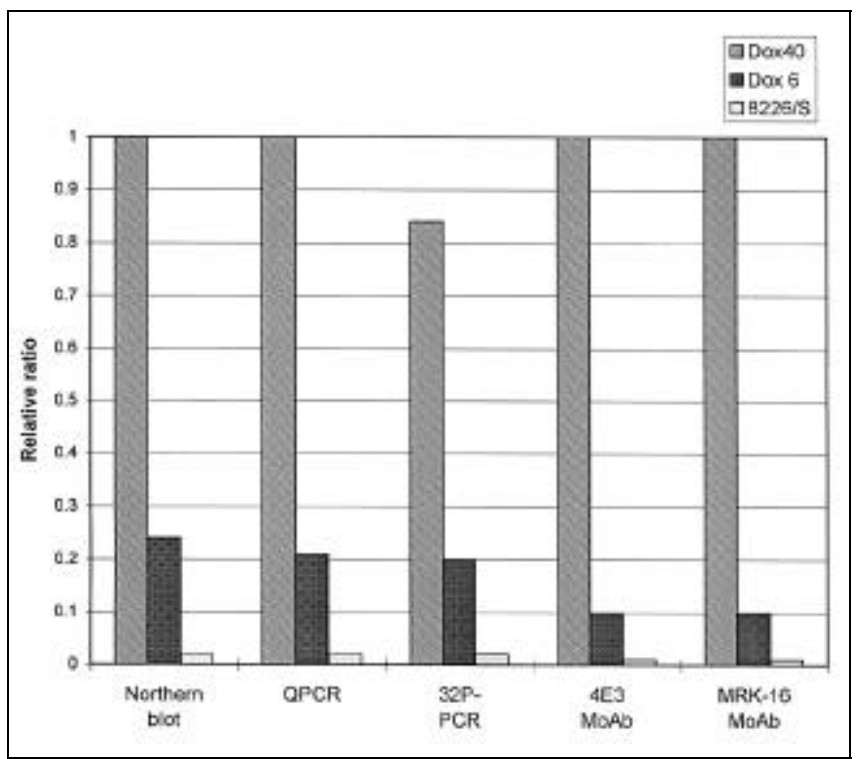

Figure 4. Relative levels of the MDR1 and P-gp expression in Dox40, Dox6 and 8226/S cell lines by different methods. Using Dox 40 expression levels by Northern blot as control (100\%), the relative levels of MDR1 measured by QPCR and ${ }^{32} \mathrm{P}-\mathrm{PCR}$ were normalized in Dox40, Dox6 and 8226/S cells. The P-gp level of Dox40 cells was determined as 100\% using 4E3 and MRK-16 antibodies. The relative level of P-gp was compared with Dox6 and $8226 / \mathrm{S}$. 
$\mathrm{ng} / \mathrm{mL} \mathrm{Rh}-123$ in $1 \mathrm{~mL}$ of RPMI- 1640 medium at $37^{\circ} \mathrm{C}$ for 15 min, washed twice in ice cold medium, and then transferred into dye-free medium with or without $10 \mu \mathrm{g} / \mathrm{mL}$ verapamil and incubated at $37^{\circ} \mathrm{C}$ for $90 \mathrm{~min}$. The cell sorting method was reported previously (3), using CD34 and CD33 antigen as cell-surface markers for fluorescence-activated cell sorting (FACS). The fluorescence labeled antibodies HPCA-2 (antiCD34) and CD33 were obtained from Becton Dickinson.

\section{RESULTS}

\section{Comparison of Detection Methods for MDR1 RNA Levels}

The cell lines Dox 40 and Dox6 are known from previous work to express different levels of the MDR1 gene, Dox40 being significantly higher than Dox6 and CEM Dox1. The $8226 / \mathrm{S}$, which is the parental cell line of Dox6 and Dox40, has no detectable MDR1 gene expression $(3,6)$. The sensitivities of $32 \mathrm{P}$ incorporation and QPCR were compared using Dox40 cells by removing separate reaction tubes from the thermal cycler at various cycle numbers and obtaining signals using each detection method. Figure 1 shows that a relatively strong signal was obtained from the QPCR method at cycle 25 , but only a weak signal using ${ }^{32} \mathrm{P}$ incorporation (ratio 12:1). To evaluate accuracy, PCR template was diluted 1:10 five times and amplified by the two methods. Figure 2 shows that the signals from the QPCR method are closer to the expected values than those obtained by ${ }^{32} \mathrm{P}$ incorporation. To evaluate the reproducibility of the entire protocol, two experiments were performed using all three lines from which the same amount of cDNA was used in each reaction. Figure $3 \mathrm{~A}$ shows that the standard deviation for QPCR ranged from $4 \%$ to $7 \%$ (mean $5.5 \pm 1.9 \%$ ), while it was $7 \%$ to $11 \%$ (mean 10.0 $\pm 3.3 \%)$ for the ${ }^{32} \mathrm{P}$ incorporation method (Figure 3B) $(P$ $<0.001)$. The relative levels of MDR1 expression in cell lines were determined by Northern dot-blot analysis, ${ }^{32} \mathrm{P}-\mathrm{PCR}$ and QPCR. Since the control gene for Northern blot ( $\beta$-actin) is different from $\beta_{2}$-M used for PCR, we normalized the relative ratios with Dox 40 set as $100 \%$. Figure 4 shows that the MDR1 expression levels determined by QPCR are better correlated with the Northern-blot data than the ${ }^{32} \mathrm{P}$ results. The ratios of P-gp measured by flow cytometry in the system cell lines Dox40, Dox6 and 8226/S were 10.6, 1.0 and 0, respectively, using the 4E3 and MRK-16 antibodies. The mRNA levels correlated well with the P-gp levels. Rhodamine efflux was $65 \%, 63 \%$ and $0 \%$ (in the presence or absence of verapamil). The QPCR ratio was 0.0072 for the CEMDox 1 cell line, significantly (3-fold) above background (0.0018). The ${ }^{32} \mathrm{P}$ PCR method failed to detect positivity (no difference with background), but flow cytometry of P-gp was positive using two different antibodies, as was the efflux study (Figure 5).

\section{Comparison of the Detection Methods in AML Patient Samples}

Three AML samples with blast counts of more than 95\% were further enriched for blasts to $99 \%$ by FACS cell sorting. The P-gp levels for the blasts were determined by flow cytometry using the MDR1-specific monoclonal antibodies MRK-16 and 4E3. The efflux activities were also determined by $\mathrm{Rh}-123$ dye retention in cells with or without verapamil.
Figure 5 shows the P-gp levels (as D values), efflux activities and two quantitative PCR data in the three AML patient samples. The AML samples represent high, medium and low or negative P-gp levels and efflux activity. However, the ${ }^{32} \mathrm{P}$ incorporation method for quantitative PCR was unable to detect differences between those samples containing high and medium levels of P-gp: the ratios of MDR $1 / \beta_{2}-\mathrm{M}$ were 0.41 and $0.40(\mathrm{SD}=11 \%)$, respectively. In contrast, by using QPCR, differences were detected between the two levels of expression. The MDR $1 / \beta_{2}-\mathrm{M}$ ratios were 0.127 and $0.097(\mathrm{SD}=$ $7 \%$ ), respectively.

\section{DISCUSSION}

Quantitation of PCR is an important objective for many studies, and different techniques have been described $(3,6,13)$. As in any other quantitative technique, the more accurate, reproducible and sensitive the detection method, the better the results should be. The comparison between the nonradioactive, electrochemiluminescence-based QPCR method and ${ }^{32} \mathrm{P}$ incorporation as a means for measuring PCR products demonstrated that QPCR has increased sensitivity. This advantage may be important for allowing the detection of amplified products earlier in PCR, before a plateau phase is reached. The reproducibility was also better for QPCR than for the ${ }^{32} \mathrm{P}$ incorporation method, as determined by SD of $4 \%$ to $7 \%$ (mean 5.5) for QPCR, and 7\% to $11 \%$ (mean 10.0) for ${ }^{32} \mathrm{P}$ incorporation PCR, respectively. In ${ }^{32} \mathrm{P}-\mathrm{PCR}$ the samples are mixed with loading dye, and subsequently loaded on the gel. During this process, sample attachment to the loading tips could cause variations. The accuracy of QPCR also appeared to be better than that observed for the ${ }^{32} \mathrm{P}$ incorporation method, as evidenced by the correlation between the QPCR results, Northern-blot data, and the protein and

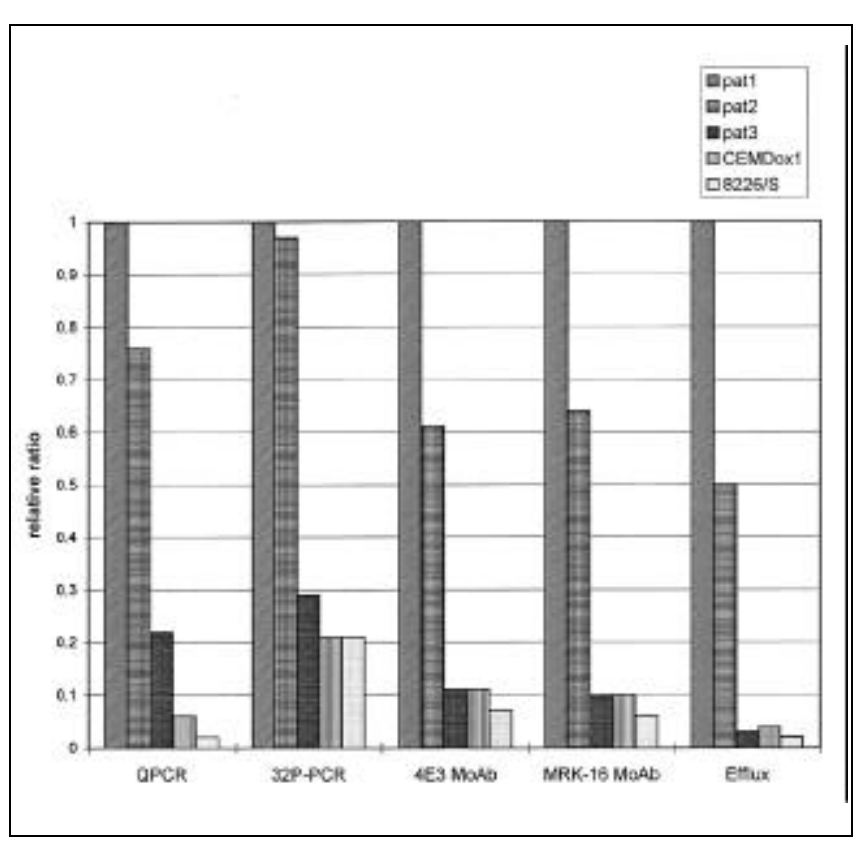

Figure 5. P-gp levels, efflux activity and MDR1 gene expression in three AML patient samples by different methods. $P$-gp, mRNA and efflux function were determined by flow cytometry and PCR (QPCR and $\left.{ }^{32} \mathrm{P}-\mathrm{PCR}\right)$. By setting the most positive sample (pat1) as $100 \%$, the relative values of other samples were compared. 
functional results obtained by flow cytometry. The AML sample, considered negative by Rh123-efflux and P-gp antibody studies, was weakly positive by ${ }^{32} \mathrm{P}$ incorporation PCR, suggesting low levels of MDR1 mRNA. A very faint band was visible on autoradiographs, and the MDR $1 / \beta_{2}$-M ratio of 0.12 suggested weak positivity. QPCR measurements, however, were 15-fold over background (ratio 0.0018) and 4-5-fold higher than the lower MDR1-expressing CEM Dox 1 cell line (ratio 0.0072). While the significance of such low levels of MDR1 is not known, only a specific and sensitive technique will be able to answer this question.

The QPCR system utilizes a biotin-labeled and a TBR-labeled primer, both of which are non-radioactive and as stable as regular unlabeled primers. In contrast, the use of a radioactive isotope may present problems in safety, handling, disposal and decay. Depending on the half-life of the isotope, the specific activity of the sample may be significantly affected during repetitions of experiments.

The time required for detecting PCR products using QPCR is 1 min per sample, with a prior 20-min bead-capture step that can be performed in batch. In contrast, the radioactivity method required the pouring and polymerization of a gel, electrophoresis and autoradiography, requiring a total time of approximately 8-12 h. The QPCR method is well suited for high-throughput applications using research and clinical samples.

\section{ACKNOWLEDGMENT}

This study is supported by Grants CA55164, CA41305 and CA57639 from National Institutes of Health. S.Z. is a recipient of the AMGEN Fellowship Award, U.C. is in part supported by a scholarship from Fondazione Catanese per lo Studio e la Cura delle Malattie Neoplastiche del Sangue (Catania-Italy).

\section{REFERENCES}

1.Chen, C.J., J.E. Chin, K. Ueda, D.P. Clark, I. Pastan, M.M. Gottesman and I.B. Roninson. 1986. Internal duplications and homology with bacterial transport proteins in the MDR1 gene from multidrug-resistant human cells. Cell 47:381-389.

2.Chomcyznski, P. and N. Sacchi. 1987. Single-step method of RNA isolation by acid guanidinium thiocyanate-phenol-choloroform extraction. Anal. Biochem. 162:156-159.

3.Drach, D., S. Zhao, J. Drach, R. Mahadevia, C. Gattringer, H. Huber and M. Andreeff. 1992. Subpopulations of normal peripheral blood and bone marrow cells express a functional multidrug resistant phenotype. Blood 80:2729-2734.

4.Gilliland, G., S. Perrin, K. Blanchard and H.F. Bunn. 1990. Analysis of cytokine mRNA and DNA: detection and quantitation by competitive polymerase chain reaction. Proc. Natl. Acad. Sci. USA 87:2725-2729.

5.Juliano. R.L. and V. Ling. 1976. A surface glycoprotein modulating drug permeability in Chinese hamster cell mutants. Biochem. Biophys. Acta 455:152-162.

6.Klimecki, W.T., B.W. Futscher, T.M. Grogan and W.S. Dalton. 1994. P-glycoprotein expression and function in circulating blood cells from normal volunteers. Blood 83:2451-2458.

7.Kuwazura,Y., A. Yoshimura, S. Hanada, A. Utsunomiya, T. Makino, K. Ishibashi, M. Kodama, M. Iwahashi, T. Arima and S.I. Akiyama. 1990. Expression of the multidrug transporter, P-glycoprotein in acute leukemic cells and correlation to clinic drug resistance. Cancer 66:868873 .

8.Marie, J.P., R. Zitton and B. Sikic. 1991. Multidrug resistance (mdr1) gene expression in adult acute leukemias: correlation with treatment outcome and in vitro drug sensitivity. Blood 78:586-592.
9.Maslak, P., S. Hegewisch-Becker, L. Godfrey and M. Andreeff. 1994. Flow cytometric determination of the multidrug-resistant phenotype in acute leukemia. Cytometry 17:84-93.

10.Meyers, M.B., L. Rittman-Grauer and J.P. O’Brien. 1989. Characterization of monoclonal antibodies recognizing a Mr 180,000 P-glycoprotein: differential expression of the Mr 180,000 and 170,000 P-glycoprotein in multidrug resistant human tumor cells. Cancer Res. 49:3209-3214.

11.Mickisch, G.H., I. Aksentijevich, V. Schoelein, L.J. Goldstein, H. Galski, C. Stahle, D.H. Sachs, I. Pastan and M.M. Gottesman. 1992. Transplantation of bone marrow cells from transgenic mice expressing the human MDR1 gene results in long-term protection against the myelosuppressive effect of chemotherapy in mice. Blood 79:1087-1093.

12.Noonan, K.E., C. Beck., T.A. Holzmayer, V. Chin, J.S. Wunder, L. Andrulis, A. Gazdar, C.L. Willman, B. Griffith, D.D. Von Hoff and I.B. Roninson. 1990. Quantitative analysis of MDR1 gene expression in human tumours by polymerase chain reaction. Proc. Natl. Acad. Sci. USA 87:7160-7164.

13.Wang, M., M.V. Doyle and D.F. Mark. 1989. Quantitation of mRNA by the polymerase chain reaction. Proc. Natl. Acad. Sci. USA 86:9717-9721.

14.Young, I.T. 1977. Proof without prejudice. Use of Kolmogorov-Smirnov test for the analysis of histograms from flow systems and other sources. J. Histochem. Cytochem. 25:935-941.

Address correspondence to Michael Andreeff, The University of Texas M.D. Anderson Cancer Center, Department of Hematology, Box 81, 1515 Holcombe Blvd., Houston, TX 77030, USA. 